\title{
50-YEAR SUITABILITY EVALUATION ON PINUS DENSIFLORA FOREST PLANTATION IN MOUNT TA, SHANDONG, CHINA
}

\author{
WANG, Y. J. ${ }^{1}-$ YAN, ${ }^{1}{ }^{1}-$ YoU, C. ${ }^{1}{ }^{1}-$ WANG, ${ }^{2}{ }^{2}-$ GAO, Y.$^{2 *}$ \\ ${ }^{1}$ Linyi Scientific Exploration Laboratory, Linyi 276037, China \\ (1344305811@qq.com,gjp428@163.com,522794855@qq.com) \\ ${ }^{2}$ Shandong Provincial Key Laboratory of Water and Soil Conservation and Environmental \\ Protection, College of Resources and Environment, Linyi University, Linyi 276005, China \\ (wangyunsd@163.com) \\ *Corresponding author \\ e-mail: gaoyuan1182@tom.com,gaoy@lyu.edu.cn \\ (Received 24 $4^{\text {th }}$ Sep 2020; accepted $14^{\text {th }}$ May 2021)
}

\begin{abstract}
In this study, with a 50-year-old Pinus densiflora forest plantation on Mount Ta as the experimental group and 50-year-old secondary forest as the control group, diameter distribution and species diversity of Pinus densiflora and secondary forests were assessed using quadrat method to analyze 4 species diversity indices and 7 soil nutrient indices, evaluate the suitability of Pinus densiflora forest plantation in Mount Ta, and provide a reference for Pinus densiflora forest plantation and plant community succession in Mount Ta even extending to Yimeng mountain area. The results indicate that: (1) Evaluated in terms of individual and population, Mount Ta is a suitable area for Pinus densiflora forest, but Pinus densiflora seedlings and saplings are significantly scarce, which will make it difficult for population to renew. (2) In terms of 4 species diversity indexes of arborous layer and shrub layer in Mount Ta, Pinus densiflora forests do not significantly different from secondary forests, while 4 species diversity indices of field layer are significantly higher in Pinus densiflora than in secondary forests. The soil contents of organic matter, total nitrogen, phosphorus and potassium and available nitrogen, phosphorus and potassium are not significantly different between Pinus densiflora and secondary forests in Mount Ta. Evaluated from the perspective of community and ecosystem, Mount Ta is a suitable area for Pinus densiflora. (3) Pinus densiflora forest plantation or long-term enclosure in this area can promote vegetation recovery.
\end{abstract}

Keywords: forest plantation, secondary forest, Pinus densiflora, diameter structure, species diversity, soil nutrients, Mount Ta

\section{Introduction}

Biodiversity and species coexistence have always been regarded as a core research topic in ecology (Maurer and Rosenzweig, 1996; Boeye et al., 2014; Thomas et al., 2018; Parvinen et al., 2020). Forest development status and potential are limited, subject to restriction of regional ecological conservation and biodiversity restoration (Hilmers et al., 2018). At present, the majority by forest resources in China are various secondary forests and plantations, attracting much attention from many scholars (Gao and Wang, 2018). Soil provides the basic condition and material basis for the forest ecosystem, which determines and restricts forestry production and forest health (Cantidio and Souza, 2019).

Pinus densiflora is naturally distributed in narrow and long intermittent manner mainly from Changbai Mountain to Yuntai Mountain across Liaodong Peninsula and Shandong Peninsula (Yin et al., 2018; Kim et al., 2019). Photophilous and cold-resistant Pinus densiflora grows fast, which is the main choice of afforestation tree species in the neutral to acid soil mountains in the distribution area (Zhang et al., 2018; Gao et al., 
2020). The Pinus densiflora in Mount Ta, Shandong mainly derives from artificial afforestation in the late 1950s to the mid-1970s followed by long-term enclosure, accounting for about $30 \%$ of Mount Ta forest area, while Wayward Pines and secondary forest account for $50 \%$ and $15 \%$, respectively.

Some scholars have conducted systematic surveys on the vegetation status of Mount Ta in 1959 (Zhou, 1962) and 2009 (Gao et al., 2011), but there has been no report on suitability evaluation of Pinus densiflora forest plantation. In this study, we chose Pinus densiflora as the experimental group and secondary forest as the control group, and diameter distribution and species types of Pinus densiflora and secondary forest were assessed using quadrat method to analyze 4 species diversity indices. 7 soil nutrient indices, definitely judge suitability of Pinus densiflora forest plantation in Mount Ta, and provide a reference for Pinus densiflora forest plantation and plant community succession in Mount Ta and even Yimeng mountain area.

Scientific hypotheses were made in this study: (1) Predicted from individual and population perspective, Mount Ta is a suitable distribution area for Pinus densiflora. (2) Predicted from the community and ecosystem perspective, the 4 species diversity indices and 7 soil nutrient parameters will not be significantly lower in Pinus densiflora of Mount Ta than in the local secondary forest.

\section{Materials and methods}

\section{Overview of the study area}

Mount Ta is located in southeastern Shandong $\left(35^{\circ} 1^{\prime}-36^{\circ} 0^{\prime} \mathrm{N}, 117^{\circ} 4^{\prime}-118^{\circ} 2^{\prime} \mathrm{E}\right)$, with an area of $204 \mathrm{~km}^{2}$, an average annual temperature of $13.4^{\circ} \mathrm{C}$, an average annual precipitation of $900 \mathrm{~mm}$, and a forest coverage rate of 85\% (Gao et al., 2011), which is now a world geopark and a national forest park.

\section{Research methods}

\section{Field investigation}

The forest community surveyed in this study is a middle-aged forest, which is in a state of natural succession in long-term (50 years) enclosure. Five repeated plots of Pinus densiflora and secondary forest were set. The plots are close to each other in similar ecological environment. The quadrat was set to: $20 \mathrm{~m} \times 30 \mathrm{~m}$. For arborous layer and shrub layer, species with $D B H \geq 5 \mathrm{~cm}$ and $<5 \mathrm{~cm}$, quantity and $D B H$ were measured (Wei et al., 2017; Yin et al., 2018). Species, quantity and grass height were measured for field layer (Wei et al., 2017; Yin et al., 2018). The soil specification was $5 \mathrm{~m} \times 5 \mathrm{~m}$, and multiple points were selected to dig up approximately $1 \mathrm{~kg}$ of soil sample, followed by bag closure (Gao and Wang, 2018). Soil organic matter was determined by titration according to LY/T 1237-1999; total nitrogen and hydrolyzable nitrogen were determined by Kjeldahl and titration according to LY/T 1228-2015; total phosphorus and available phosphorus were determined by alkali fusion-molybdenum antimony anti-spectrophotometry and colorimetry according to LY/T 1232 -2015; total potassium and available potassium were determined by atomic absorption spectrophotometry according to LY/T 1234-2015. 


\section{Data analysis}

In this study, diameter structure was used to analyze the population types (Gao et al., 2013): Grade I , $D B H<2.5 \mathrm{~cm}$; grade II , $2.5 \mathrm{~cm} \leq D B H<7.5 \mathrm{~cm}$; grade III, $7.5 \mathrm{~cm} \leq$ $D B H<22.5 \mathrm{~cm}$; grade IV $D B H \geq 22.5 \mathrm{~cm}$. Extended species, I + II $>$ IV or $\mathrm{I}+\mathrm{II}>\mathrm{III}$; secluded species, IV $>$ I + II or III $>$ I + II ; stable invasive species, I $>$ II , III $=I V=0$; random invasive species, I or $I I \approx 0, I I I=I V=0$ (Gao et al., 2013).

The 4 plant diversity indices include richness index $(S)$, Shannon-Wiener diversity index $(H)$, Simpson diversity index $(P)$ and Pielou evenness index $(E)$ (Whittaker, 1972; Kompała-Bąba et al., 2019).

$$
\begin{gathered}
S=\text { number of plant species in the plot } \\
H=\sum_{i=1}^{s}\left(P_{i} \ln P_{i}\right) \\
P=\sum_{i=1}^{1-\sum_{i}^{s} P_{i}} \\
E=H / \mathrm{n} S
\end{gathered}
$$

IBM SPSS 21.0 (Version 21.0, Armonk, NY) was used for statistical analysis. P values $<0.05$ were considered significant.

\section{Results}

\section{Diameter structure and arbor species types}

Expanded species Quercus variabilis, Robinia pseudoacacia and Acer truncatum, a total of three species (Table 1), of which Robinia pseudoacacia is the pioneer tree species in Mount Ta artificial afforestation, Quercus variabilis and Acer truncatum are zonal native plants in Mount Ta forest.

Secluded species Pinus densiflora, Pinus thunbergii and Larix kaempferi, a total of three species (Table 1), which are pioneer tree species in Mount Ta artificial afforestation.

Stable invasive species Fraxinus rhynchophylla, Sorbus alnifolia, Diospyros lotus, Cerasus serrulata G. Don ex London, Quercus dentata, Acer saccharum, Albizia kalkora, Pistacia chinensis, Cerasus tomentosa, Dalbergia hupeana, Quercus acutissima, Cotinus coggygria and Celtis koraiensis, 13 Species (Table 1). Except Acer saccharum and Cerasus tomentosa are cultivated escaped species, the remaining 11 species are zonal native plants in Mount Ta forest.

Random invasive species Ulmus macrocarpa, Symplocos paniculata, Lindera obtusiloba, Ailanthus altissima, Sorbus pohuashanensis, Pyrus calleryana, Carpinus turczaninowii, Morus alba and Celtis sinensis (a total of 9 species) (Table 1), all of which are zonal native plants in Mount Ta. 
Table 1. Arbor diameter distribution of Pinus densiflora and secondary forest in Mount Ta, China

\begin{tabular}{|c|c|c|c|c|}
\hline & $\begin{array}{r}\text { I level } \\
<2.5 \mathrm{~cm} \\
\end{array}$ & \begin{tabular}{c|} 
II level \\
$2.5 \mathrm{~cm}-7.5 \mathrm{~cm}$ \\
\end{tabular} & $\begin{array}{c}\text { III level } \\
7.5 \mathrm{~cm}-22.5 \mathrm{~cm} \\
\end{array}$ & $\begin{array}{r}\text { IV level } \\
\geq 22.5 \mathrm{~cm} \\
\end{array}$ \\
\hline Quercus variabilis & 283 & 86 & 43 & 4 \\
\hline Pinus densiflora & 5 & 13 & 135 & 12 \\
\hline Robinia pseudoacacia & 57 & 22 & 23 & 3 \\
\hline Fraxinus rhynchophylla & 71 & 8 & 0 & 0 \\
\hline Sorbus alnifolia & 59 & 1 & 0 & 0 \\
\hline Diospyros lotus & 37 & 10 & 0 & 0 \\
\hline $\begin{array}{c}\text { Cerasus serrulata G. Don ex } \\
\text { London }\end{array}$ & 42 & 1 & 0 & 0 \\
\hline Quercus dentata & 39 & 2 & 0 & 0 \\
\hline Acer saccharum & 23 & 1 & 0 & 0 \\
\hline Albizia kalkora & 22 & 1 & 0 & 0 \\
\hline Acer truncatum & 10 & 6 & 5 & 0 \\
\hline Pistacia chinensis & 12 & 6 & 0 & 0 \\
\hline Cerasus tomentosa & 14 & 3 & 0 & 0 \\
\hline Pinus thunbergii & 0 & 3 & 14 & 0 \\
\hline Celtis sinensis & 2 & 14 & 0 & 0 \\
\hline Dalbergia hupeana & 9 & 3 & 0 & 0 \\
\hline Quercus acutissima & 6 & 6 & 0 & 0 \\
\hline Cotinus coggygria & 6 & 5 & 0 & 0 \\
\hline Ulmus macrocarpa & 7 & 0 & 0 & 0 \\
\hline Celtis koraiensis & 6 & 1 & 0 & 0 \\
\hline Symplocos paniculata & 6 & 0 & 0 & 0 \\
\hline Lindera obtusiloba & 5 & 0 & 0 & 0 \\
\hline Ailanthus altissima & 4 & 0 & 0 & 0 \\
\hline Sorbus pohuashanensis & 4 & 0 & 0 & 0 \\
\hline Pyrus calleryana & 1 & 1 & 0 & 0 \\
\hline Larix kaempferi & 0 & 1 & 1 & 0 \\
\hline Carpinus turczaninowii & 1 & 0 & 0 & 0 \\
\hline Morus alba & 1 & 0 & 0 & 0 \\
\hline total & 732 & 194 & 221 & 19 \\
\hline
\end{tabular}

\section{Species diversity}

Arborous layer, richness: Pinus densiflora > Secondary forest, Shannon-Wiener diversity, Simpson diversity and Pielou evenness: Pinus densiflora $<$ Secondary forest ( $p>0.05)$; Shrub layer, richness and Shannon-Wiener diversity: Pinus densiflora > Secondary forest, Simpson diversity and Pielou evenness: Pinus densiflora $<$ secondary forest $(p>0.05)$; field layer, 4 species diversity index: Pinus densiflora $>$ secondary forest $(p<0.05)$ (Figure 1). 

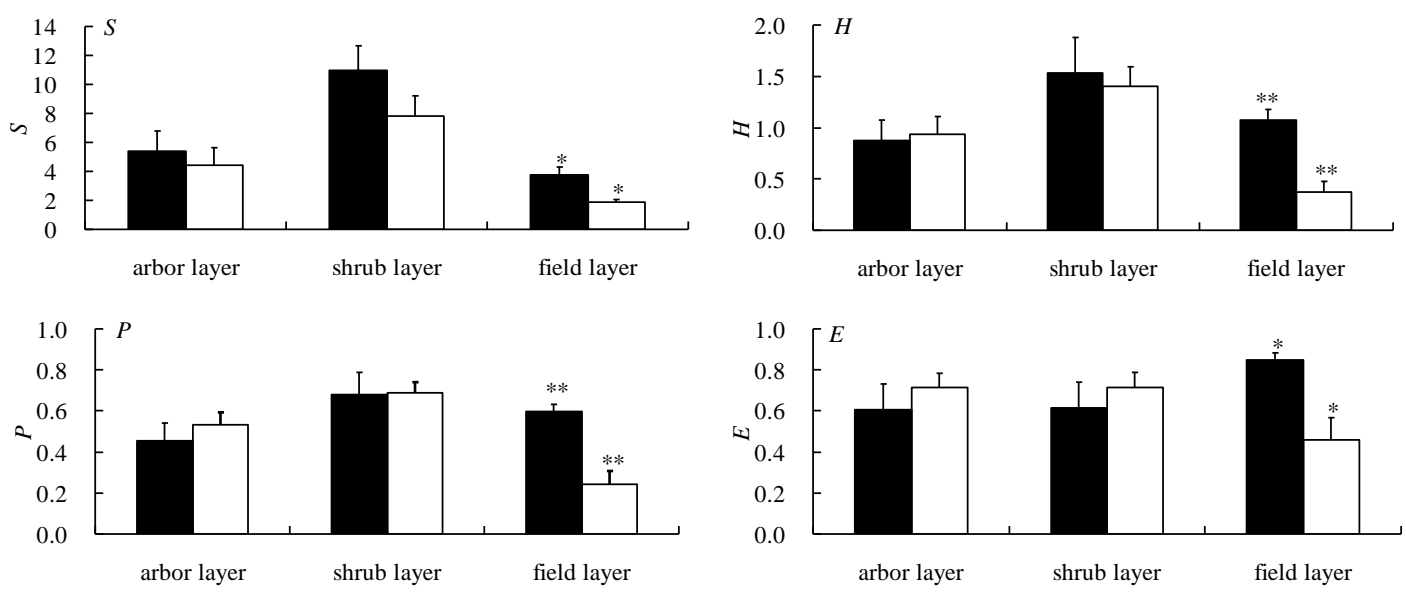

Figure 1. Differences in plant species diversity between arbor layer, shrub layer and field layer of Pinus densiflora forests and secondary forests in Mount Ta (mean + standard error)

-, Pinus densiflora forests; $\square$, secondary forests

$*, p<0.05 ; * *, p<0.01$

\section{Soil nutrients}

The seven soil nutrient parameters of Pinus densiflora and secondary forest in Mount Ta include: soil organic matter, total nitrogen, hydrolyzable nitrogen and available potassium content: that of Pinus densiflora $>$ secondary forest $(p>0.05)$, soil total phosphorus, total potassium and available phosphorus content: that of Pinus densiflora $<$ Secondary forest $(p>0.05)$ (see Table 2).

Table 2. Differences in soil organic matter, total nitrogen, phosphorus and potassium, hydrolytic nitrogen, available phosphorus and potassium between Pinus densiflora forests and secondary forests in Mount Ta, Shandong, China (mean \pm standard error)

\begin{tabular}{c|c|c}
\hline & Pinus densiflora forests & secondary forests \\
\hline Soil organic matter $\left(\mathrm{g} \cdot \mathrm{kg}^{-1}\right)$ & $48.98 \pm 8.62$ & $42.40 \pm 8.46$ \\
Total nitrogen $\left(\mathrm{g} \cdot \mathrm{kg}^{-1}\right)$ & $1.54 \pm 0.33$ & $1.23 \pm 0.30$ \\
Hydrolytic nitrogen $\left(\mathrm{mg} \cdot \mathrm{kg}^{-1}\right)$ & $150.40 \pm 41.36$ & $141.60 \pm 27.39$ \\
Total phosphorus $\left(\mathrm{g} \cdot \mathrm{kg}^{-1}\right)$ & $0.36 \pm 0.04$ & $0.45 \pm 0.05$ \\
Available phosphorus $\left(\mathrm{mg} \cdot \mathrm{kg}^{-1}\right)$ & $16.86 \pm 4.28$ & $19.26 \pm 6.02$ \\
Total potassium $\left(\mathrm{g} \cdot \mathrm{kg}^{-1}\right)$ & $8.23 \pm 0.34$ & $9.44 \pm 1.54$ \\
Available potassium $\left(\mathrm{mg} \cdot \mathrm{kg}^{-1}\right)$ & $31.76 \pm 4.42$ & $28.94 \pm 3.42$ \\
\hline
\end{tabular}

\section{Conclusion and discussion}

(1) In the survey, 3 species of extended species and secluded species, 13 species of stable invasive species and 9 species of random invasive species were discovered. Where, Pinus densiflora, Pinus thunbergii, Robinia pseudoacacia and Larix kaempferi are pioneer tree species in Mount Ta artificial afforestation, Acer saccharum and Cerasus tomentosa are cultivated escaped species, Quercus variabilis, Acer truncatum, Stable invasive species Fraxinus rhynchophylla, Sorbus alnifolia, Diospyros lotus, 
Cerasus serrulata G. Don ex London, Quercus dentata, Albizia kalkora, Pistacia chinensis, Dalbergia hupeana, Quercus acutissima, Cotinus coggygria, Celtis koraiensis, Ulmus macrocarpa, Symplocos paniculata, Lindera obtusiloba, Ailanthus altissima, Sorbus pohuashanensis, Pyrus calleryana, Carpinus turczaninowii, Morus alba and Celtis sinensi are zonal native plants in Mount Ta forest. Pinus densiflora can go through the entire life history and reproduction process in Mount Ta. Evaluated in terms of individual and population, Mount Ta is a suitable area for Pinus densiflora forest, but Pinus densiflora seedlings and saplings are significantly scarce, which will make it difficult for population to renew.

(2) In terms of 4 species diversity indexes of arborous layer and shrub layer in Mount Ta, Pinus densiflora has no significant difference from secondary forests, while 4 species diversity indexes of field layer are significantly higher in Pinus densiflora than in secondary forests. The soil organic matter, total nitrogen, phosphorus and potassium and available nitrogen, phosphorus and potassium contents in soil are not significantly different between Pinus densiflora and secondary forests in Mount Ta. Evaluated from the perspective of community and ecosystem, Mount Ta is a suitable area for Pinus densiflora.

(3) From the 1950s to the 1970s, Pinus densiflora was planted on a large scale during Mount Ta forest vegetation recovery. After 50 years of enclosure and natural succession, the original Pinus densiflora still exists on a large scale, but secondary native tree species like Quercus variabilis have been restored to a large extent, which have successfully infiltrated into Pinus densiflora forest, and some areas have even formed forests, indicating that Pinus densiflora forest plantation or long-term enclosure in this area can promote vegetation recovery.

Acknowledgements. Funded by the Fund of Shandong Provincial Key Laboratory of Water and Soil Conservation and Environmental Protection, Linyi University, NO.STKF201906 and National Natural Science Foundation of China, NO. 32071630.

\section{REFERENCES}

[1] Boeye, J., Kubisch, A., Bonte, D. (2014): Habitat structure mediates spatial segregation and therefore coexistence. - Landscape Ecology 29: 593-604.

[2] Cantidio, L. S., Souza, A. F. (2019): Aridity, soil and biome stability influence plant ecoregions in the atlantic forest, a biodiversity hotspot in south america. - Ecography 42: 1887-1898.

[3] Gao, Y., Chen, Y. F., Dong, H., Ci, H. X. (2011): Vegetation and species diversity change analysis in 50 years in Tashan Mountain, Shandong Province, China. - Acta Ecologica Sinica 31(20): 5984-5991. (in Chinese).

[4] Gao, Y., Zhu, K. S., Hao, J. C., Xu, L. S. (2013): An evaluation of the afforestation outcome of six tree species in more than 40 years in Mengshan Mountain, Shandong Province, China. - Chinese Journal of Plant Ecology 37(8): 728-738. (in Chinese).

[5] Gao, Y., Wang, Y. (2018): Medium and long-term influences of typical plantations on surface soil nutrients in the temperate zone of Mount Meng, China. - Applied Ecology and Environmental Research 16(5): 6385-6393.

[6] Gao, Y., Wang, Y., Guan, J. H. (2020): Study of Kin Recognition and Physiological Strategies of Adjacent Black Pines (Pinus thunbergii). - International Journal Ofagriculture and Biology 23(3): 555-558. 
[7] Hilmers, T., Friess, N., Bssler, C., Heurich, M., Brandl, R., Pretzsch, H., Seidl, R., Müller, J. (2018): Biodiversity along temperate forest succession. - Journal of Applied Ecology. DOI: 10.1111/1365-2664.13238.

[8] Kim, C., Kim, S., Baek, G., Yang, A. R. (2019): Carbon and nitrogen responses in litterfall and litter decomposition in red pine (pinus densiflora s. et z.) stands disturbed by pine wilt disease. - Forests 10: 244. DOI:10.3390/f10030244.

[9] Kompała-Bąba, A., Bierza, W., Błońska, A., Sierka, E., Magurno, F., Chmura, D., Besenyei, L., Radosz, Ł., Woźniak, G. (2019): Vegetation diversity on coal mine spoil heaps - how important is the texture of the soil substrate? - Biologia 74: 419-436.

[10] Maurer, B. A., Rosenzweig, M. L. (1996): Species diversity in space and time. - Ecology 77: 1314.

[11] Parvinen, K., Metz, J. A. J., Dieckmann, U. (2020): Environmental dimensionality determines species coexistence. - Journal of Theoretical Biology: 110280. DOI: 10.1016/j.jtbi.2020.110280.

[12] Thomas, C., Georges, K., Benoît, C., Xavier, M. (2018): Managing tree species diversity and ecosystem functions through coexistence mechanisms. - Annals of Forest Science 75(3): 65-75.

[13] Wei, J. J., Gao, Y., Zhao, W. G., Liu, J. (2017): Hillside topographic pattern of shrub and herb diversity of forest in Mount Tai of China. - Journal of Environmental Protection and Ecology 18(2): 571-580.

[14] Whittaker, R. H. (1972): Evolution and measurement of species diversity. - Taxon 21(23): 213-251.

[15] Yin, X. D., Gao, Y., Liu, J., Zhao, W. G. (2018): Influence of scenic road corridor to plant diversity in Kunyu Mountain, China. - Applied Ecology and Environmental Research 16(2): 1461-1469.

[16] Zhang, Z. X., Gao, Y., Zhao, Y. J. (2018): Study on allelopathy of three species of Pinus in North China. - Applied Ecology and Environmental Research 16(5): 6409-6417.

[17] Zhou, G. Y. (1962): Vegetation in Tashan, Shandong. - Journal of Shandong University (Natural Science Edition) 12(3): 53-67. (in Chinese). 